\title{
ANALISIS VOLATILITAS HARGA SAHAM TERKATEGORI INDEKS KONSTITUEN DI BURSA EFEK INDONESIA DENGAN PENGGUNAAN SIMULASI MONTE CARLO
}

\author{
Baiq Nurul Suryawati ${ }^{1}$, Laila Wardani ${ }^{2}$, Sulaeman Sarmo $^{3}$ \\ ${ }^{1}$ Fakultas Ekonomi dan Bisnis Universitas Mataram,nurul.suryawati@unram.ac.id \\ ${ }^{2}$ Fakultas Ekonomi dan Bisnis Universitas Mataram, elawardani.mtr@unram.ac.id \\ ${ }^{3}$ Fakultas Ekonomi dan Bisnis Universitas Mataram, sarmo_sulaimani@unram.ac.id
}

\begin{abstract}
ABSTRAK
Selama ini volatilitas digunakan untuk mengukur derajat kepekaan dari adanya fluktuasi data runtun waktu, hal ini memberi implikasi bahwa penggunaan volatilitas memberikan gambaran akan adanya risiko. Selanjutnya, salah satu teknik yang dapat mengakomodasi kondisi ini adalah Monte Carlo Simulation (MCS) atau Simulasi Monte Carlo. Metode pengukuran volatilitas dengan menggunakan teknik statistik dengan menggunakan angka pembangkit acak. Penggunaan Simulasi Monte Carlo untuk menganalisis volatilitas selanjutnya dilakukan agar risiko dapat diukur dengan lebih akurat berdasarkan pembangkit nilai acak yang dihasilkan oleh pengulangan sebanyak 1000 iteration, yang didesain untuk menggambarkan volatilitas dari suatu aset tertentu.
\end{abstract}

Kata Kunci: Volatilitas, Harga Saham, Simulasi Monte Carlo

\section{ABSTRACT}

Volatility used to measure degree of volatility as a fluctuation of time series data, this implies that volatility could use as a measurement of risk. Furthermore, to conduct calculation of Value at Risk, Monte-Carlo Simulation provides statistics technique to revive several random numbers. Monte-Carlo Simulation analyzes volatility more precisely as it revive random based on probability provide by several data series for 1000 iteration. This measurement of volatility will measure risk of stock prices, as it is also reflect of certain assets.

Keywords: Volatility, Stock Prices, Monte-Carlo Simulation

\section{Latar Belakang}

\section{PENDAHULUAN}

Pasar modal adalah salah satu tempat yang ideal untuk berinvestasi dimana banyak perusahaan dengan tata kelola relatif baik menawarkan sekuritas mereka untuk diperjual-belikan. Bagi para investor, pasar modal diharapkan dapat memberi keuntungan yang lebih daripada yang ditawarkan perbankan. Di sisi lain, perusahaan yang mencari modal di pasar modal diikat oleh aturan yang ketat. Hal ini disebabkan adanya beberapa syarat dari pasar modal yang harus dipenuhi seperti harus tercatat mampu memperoleh laba minimal selama kurang lebih tiga tahun berturut-turut, serta memiliki laporan keuangan yang terlaporkan/tercatat dengan baik.

Pasar modal umumnya menawarkan beberapa produk sekuritas yaitu, obligasi, saham dan derivatif. Di dalam investasi, terutama investasi pada saham, salah satu dari banyak cara untuk menyeleksi saham apa yang harus dibeli adalah dengan menggunakan indeks. Ada banyak indeks di bursa efek Indonesia, yang paling dikenal adalah Indeks Harga Saham Gabungan (IHSG) terdiri dari hampir seluruh saham dalam 
bursa. Selain itu, dikenal pula LQ45 dan IDX30 yang terdiri dari 45 saham dan 30 saham dengan market cap terbesar dan liquid. Investor dengan preferensi saham syariah juga memiliki indeksnya sendiri yaitu Jakarta Islamic Index (JII).

Pembagian indeks dilakukan juga untuk tiap sektor usaha dimana Bursa Efek Indonesia membaginya menjadi sembilan (9) indeks sektoral yaitu AGRI, BASIC-IND, CONSUMER, FINANCE, INFRASTRUCTURE, MINING, MISC-IND, PROPERTY dan TRADE. Selanjutnya, ada lagi indeks yang dibuat oleh media atau perusahaan yang disebut indeks konstituen, seperti KOMPAS 100, INVESTOR 33, PEFINDO 25, BISNIS-27, SMInfra18 dan lain-lain. Indeks terkategori konstituen dalam hal ini lebih populer dibandingkan indeks lainnya, hal ini dikarenakan screening process yang dilakukan oleh lembaga atau perusahaan yang membuatnya.

Diantara berbagai indeks konstituen yang telah disebutkan, gambar berikut merangkum perbandingan komposisi salah satu indeks konstituen yaitu SMInfra18 dibandingkan dengan saham lainnya. Gambar berikut menunjukkan bagaimana sahamsaham dari berbagai macam sektor membentuk komposisi dari berbagai indeks yang ada di Bursa Efek Indonesia. Pembagian sektor terpetakan merata untuk IHSG dan Indeks LQ 45, sementara SMInfra18, sesuai dengan peruntukkannya yang merupakan kelompok saham-saham yang bergerak di bidang infrastruktur dengan kapitalisasi pasar terbaik menunjukkan pemusatan pada sektor Industri Dasar dan Kimia; Infrastruktur, Utilitas dan Transportasi; Properti dan Real Estate; serta perdagangan, Jasa dan Investasi.

Gambar 1. Perbandingan Komposisi Sektoral Indeks SMInfra18 dengan Indeks Lainnya

\begin{tabular}{|c|c|c|c|c|c|c|}
\hline $\begin{array}{l}\text { KOMPOSIS! } \\
\text { SEKTORAL" }\end{array}$ & $\begin{array}{l}\text { Indeks } \\
\text { SMinfra18 } \\
\end{array}$ & Indeks LQ-45 & Indeks IDX30 & Indeks III & $\begin{array}{l}\text { Indeks } \\
\text { Infobank } 15\end{array}$ & IHSG \\
\hline Pertanian (JAKAGRI) & - & $2,29 \%$ & - & $3,16 \%$ & - & $3.17 \%$ \\
\hline $\begin{array}{l}\text { Industri Dasar dan } \\
\text { Kimia (JAKBIND) }\end{array}$ & $22,57 \%$ & $8,98 \%$ & $8,78 \%$ & $12,30 \%$ & - & $8,26 \%$ \\
\hline $\begin{array}{l}\text { Industri Barang } \\
\text { Konsumsi (JAKCONS) }\end{array}$ & - & $18.03 \%$ & $19,63 \%$ & $22,76 \%$ & - & $15,06 \%$ \\
\hline Keuangan (JAKFIN) & - & $28,32 \%$ & $28,91 \%$ & - & $100,00 \%$ & $24,60 \%$ \\
\hline $\begin{array}{l}\text { Infrastruktur, Utilitas, } \\
\text { dan Transportasi } \\
\text { (JAKINFR) }\end{array}$ & $62,07 \%$ & $15,83 \%$ & $17.24 \%$ & $24.15 \%$ & - & $13,51 \%$ \\
\hline $\begin{array}{l}\text { Aneka Industri } \\
\text { (JAKMMIND) }\end{array}$ & - & $10,73 \%$ & $11,10 \%$ & $15,55 \%$ & - & $8,37 \%$ \\
\hline $\begin{array}{l}\text { Pertambangan } \\
\text { (JAKMINE) }\end{array}$ & - & $5,46 \%$ & $4,43 \%$ & $6,38 \%$ & - & $6,92 \%$ \\
\hline $\begin{array}{l}\text { Properti dan Real } \\
\text { Estate (JAKPROP) }\end{array}$ & $3,20 \%$ & $3,36 \%$ & $2,86 \%$ & $5,36 \%$ & - & $6,16 \%$ \\
\hline $\begin{array}{l}\text { Perdagangan, Jasa, } \\
\text { dan Investasi } \\
\text { (JAKTRAD) }\end{array}$ & $12,16 \%$ & $6,99 \%$ & $7.06 \%$ & $10,35 \%$ & - & $13,94 \%$ \\
\hline
\end{tabular}

Sumber: PT. SMI

Pengetahuan investor akan pengelompokan saham tersebut selanjutnya akan membantu investor untuk menentukan preferensi investasi mereka, selanjutnya penelitian ini akan menelaah berbagai alternatif yang tersedia untuk investor. Selain dari pengelompokkan indeks, perbandingan volatilitas masing-masing saham yang masuk dalam kelompok tersebut, umumnya juga menjadi pertimbangan didalam investasi.

Volatilitas adalah pengukuran statistik untuk fluktuasi harga selama periode tertentu. Ukuran tersebut menunjukkan penurunan dan peningkatan harga dalam periode yang pendek dan tidak mengukur tingkat harga, namun derajat variansinya dari satu periode ke periode berikutnya. Volatilitas yang tinggi mencerminkan karakteristik penawaran dan permintaan yang tidak biasa. Biasanya volatilitas diestimasi dengan cara menghitung standar deviasi dari perubahan harga dalam waktu tertentu, yang menentukan seberapa cepat data berubah dengan keacakannya. Secara umum volatilitas 
mengukur rata-rata fluktuasi dari data runtun waktu. Namun hal ini dikembangkan lebih jauh dengan menekankan pada nilai variansi dari data. Dari sini dapat dikatakan bahwa volatilitas sebagai nilai variansi dari data fluktuasi (Sunaryo, 2007).

Gambar berikut menunjukkan fluktuasi harga saham dari saham terkategori indeks SMInfra 18. Perubahan harga berbanding dengan bulan Januari bervariasi dari 1.125 sampai 125 . Tajamnya perubahan ini menunjukkan indikasi tingginya volatilitas saham-saham yang terkategori SMInfra 18 termaksud.

Gambar 2. Kutipan Harga Saham terkategori SMInfra18 periode Februari 2018

\begin{tabular}{|c|c|c|c|c|c|c|c|c|c|c|c|c|}
\hline No & Kode & Previous & High & Low & Last & Change & $\%$ & Volume & Value & Freq & Bid & Offer \\
\hline 1 & ADHI & 2.160 & 2.180 & 2.120 & 2.120 & -40 & $-1,85$ & 6.254 .200 & 13.333 .840 .000 & 790 & 2.110 & 2.120 \\
\hline 2 & AKRA & 5.800 & 5.875 & 5.750 & 5.775 & -25 & $-0,43$ & 7.836 .700 & 45.613 .865 .000 & 1.464 & 5.775 & 5.825 \\
\hline 3 & BBNI & 9.400 & 9.525 & 9.025 & 9.525 & 125 & 1,33 & 28.363 .500 & 266.194 .312 .500 & 2.725 & 9.500 & 9.525 \\
\hline 4 & BBRI & 3.640 & 3.680 & 3.550 & 3.680 & 40 & 1,10 & 226.448 .600 & 822.933 .565 .000 & 8.364 & 3.670 & 3.680 \\
\hline 5 & BMRI & 8.000 & 7.950 & 7.700 & 7.925 & -75 & $-0,94$ & 77.786 .000 & 613.417 .512 .500 & 3.916 & 7.900 & 7.925 \\
\hline 6 & EXCL & 2.550 & 2.540 & 2.460 & 2.500 & -50 & $-1,96$ & 13.332 .700 & 33.265 .257 .000 & 1.821 & 2.490 & 2.500 \\
\hline 7 & INTP & 20.000 & 20.100 & 19.550 & 19.550 & -450 & $-2,25$ & 4.219 .600 & 82.865 .185 .000 & 2.715 & 19.525 & 19.550 \\
\hline 8 & ISAT & 5.300 & 5.350 & 5.200 & 5.200 & -100 & $-1,89$ & 164.100 & 856.750 .000 & 82 & 5.175 & 5.200 \\
\hline 9 & JSMR & 4.920 & 4.960 & 4.790 & 4.840 & -80 & $-1,63$ & 11.518 .900 & 55.911 .973 .000 & 2.575 & 4.830 & 4.840 \\
\hline 10 & KRAS & 478 & 480 & 460 & 460 & -18 & $-3,77$ & 10.058 .400 & 4.700 .256 .200 & 783 & 460 & 462 \\
\hline 11 & MEDC & 1.285 & 1.300 & 1.220 & 1.230 & -55 & $-4,28$ & 66.766 .000 & 83.022 .331 .500 & 4.223 & 1.230 & 1.240 \\
\hline 12 & PGAS & 2.300 & 2.330 & 2.210 & 2.260 & -40 & $-1,74$ & 122.158 .600 & 275.850 .618 .000 & 6.853 & 2.260 & 2.270 \\
\hline 13 & PTPP & 2.900 & 2.930 & 2.690 & 2.750 & -150 & $-5,17$ & 37.125 .300 & 102.048 .345 .000 & 3.949 & 2.750 & 2.760 \\
\hline 14 & SMGR & 10.500 & 10.725 & 10.350 & 10.525 & 25 & 0,24 & 9.306 .800 & 98.045 .527 .500 & 3.135 & 10.525 & 10.550 \\
\hline 15 & TBIG & 5.725 & 5.825 & 5.625 & 5.800 & 75 & 1,31 & 2.517 .000 & 14.562 .850 .000 & 394 & 5.775 & 5.800 \\
\hline 16 & TLKM & 3.930 & 3.950 & 3.820 & 3.820 & -110 & $-2,80$ & 208.216 .200 & 801.471 .799 .000 & 12.463 & 3.820 & 3.840 \\
\hline 17 & UNTR & 33.700 & 33.500 & 32.550 & 32.575 & -1.125 & $-3,34$ & 9.680 .100 & 316.868 .452 .500 & 7.496 & 32.550 & 32.575 \\
\hline 18 & WIKA & 1.745 & 1.760 & 1.705 & 1.710 & -35 & $-2,01$ & 15.864 .400 & 27.312 .120 .500 & 2.206 & 1.710 & 1.715 \\
\hline
\end{tabular}

Sumber: Bursa Efek Indonesia

Berdasarkan data awal pada beberapa gambar diatas, maka penelitian ini selanjutnya akan menganalisis volatilitas harga saham terkategori indeks konstituen dengan menggunakan Simulasi Monte-Carlo. Diketahui bahwa indeks sebagai acuan penentuan strategi investasi adalah sangat penting. Selanjutnya dikemukakan oleh Firdaus (2004) bahwa strategi investasi pasif dengan cara indexing merupakan salah satu alternatif untuk mengurangi transaction cost. Selain itu, Firdaus juga mengemukakan bahwa berdasarkan regresi data bulanan diketahui bahwa $8.49 \%$ perubahan dari return indeks tertentu JII dipengaruhi oleh return pasarnya, dalam hal ini IHSG. Lebih lanjut lagi, hasil penelitian tersebut membuktikan bahwa return dari JII selama periode pengamatan outperform jika dibandingkan dengan IHSG.

Adapun penelitian ini bertujuan untuk melengkapi rangkaian penelitian sebelumnya, terutama yang berkaitan dengan rentang waktu penelitian yang lebih lama dan perbandingan terhadap alternatif investasi dalam variasi indeks konstituen yang lebih luas. Hal ini bertujuan agar dapat diperoleh gambaran yang komprehensif tentang volatilitas harga saham dari berbagai macam variasi indeks konstituen yang sudah terlebih dahulu mengalami proses screening atau seleksi, sesuai dengan acuannya masing-masing.

\section{Rumusan Masalah}

Beberapa permasalahan yang dapat dirumuskan antara lain:

1. Bagaimanakah mengukur volatilitas harga saham terkategori indeks konstituen dengan menggunakan simulasi Monte-Carlo? 
2. Apakah terdapat perbedaan yang signifikan antara volatilitas harga saham dengan menggunakan simulasi Monte Carlo pada saham terkategori indeks konstituen?

\section{Pasar Modal}

\section{TINJAUAN LITERATUR}

Pasar modal adalah sebuah lembaga yang menghubungkan antara pihak yang defisit dana dengan pihak yang surplus dana. Didalam menjalankan fungsi ini pasar modal disebut menjalankan fungsinya sebagai intermediaries. Tandelilin (2010) mendefinisikan pasar modal sebagai pertemuan antara pihak yang memiliki kelebihan dana dengan pihak yang membutuhkan dana dengan cara memperjual-belikan sekuritas. Sementara itu, pasar modal menurut Gitman (2003) dijelaskan sebagai:

"Capital Market is a market enable suppliers and demanders of long term funds to make transactions."

Viney (2007) kemudian mendefinisikan pasar saham sebagai lembaga formal yang memfasilitasi pembelian, penjualan maupun penerbitan sebuah sekuritas.

"Share Market is a formal exchange that facilitates the issue, buying and selling of equity securities."

Berdasarkan beberapa definisi diatas, maka pasar modal dapat kita artikan sebagai lembaga dimana sekuritas diperdagangkan. Sekuritas yang dimaksud dapat berupa obligasi, saham, maupun turunannya.

\section{Macam-macam Indeks Harga Saham di Bursa Efek Indonesia}

Indeks harga saham merupakan indikator utama yang menggambarkan pergerakan harga saham sekaligus merupakan salah satu leading indicator bagi perekonomian. Di pasar modal sebuah indeks diharapkan memiliki lima fungsi :

1. sebagai indikator tren pasar,

2. sebagai indikator tingkat keuntungan,

3. sebagai tolok ukur (benchmark) performa suatu portofolio,

4. memfasilitasi pembentukan portofolio dengan strategi pasif, dan

5. memfasilitasi berkembangnya produk derivatif.

Di Bursa Efek Indonesia terdapat sepuluh beberapa indeks (IDX, 2010), antara lain:

1. Indeks individual, menggunakan indeks harga masing-masing saham terhadap harga dasarnya.

2. Indeks harga saham sektoral, menggunakan semua saham yang termasuk dalam masing-masing sektor. Di BEI indeks sektorial terbagi atas sembilan sektor yaitu:

a. Sektor-sektor primer (ekstraktif) : pertanian, pertambangan.

b. Sektor-sektor sekunder (industri manufaktur) : industri dasar dan kimia, aneka industri, industri barang konsumsi.

c. Sektor-sektor tersier (jasa) : properti dan real estate, transportasi dan infrastruktur, keuangan, perdagangan, jasa dan investasi.

3. Indeks LQ 45, menggunakan 45 saham yang terpilih berdasarkan likuiditas perdagangan saham dan disesuaikan setiap enam bulan (setiap awal bulan Pebruari dan Agustus) dengan demikian saham yang terdapat dalam indeks tersebut akan selalu berubah.

4. Jakarta Islamic Index (JII), indeks ini diperuntukkan bagi saham-saham syariah atau saham-saham yang telah dinyatakan halal oleh Dewan Syariah Nasional. Saat ini baru terdiri dari 30 saham halal dan disesuaikan setiap enam bulan sekali (setiap 
awal Januari dan Juli). Dengan demikian saham yang terdapat dalam indeks tersebut akan selalu berubah.

5. Indeks Harga Saham Gabungan (IHSG) atau composite share price index, menggunakan semua saham yang tercatat sebagai komponen perhitungan indeks.

6. Indeks Kompas 100 yaitu 100 saham yang terpilih berdasarkan pertimbangan faktor likuiditas, kapitalisasi pasar dan performa fundamental dari saham-saham tersebut. Indeks ini mulai dilucurkan 13 Juli 2007 agar dapat dimanfaatkan oleh investor, pengelola portofolio dan fund manager agar dapat dijadikan acuan dalam menciptakan kreatifitas (inovasi) pengelolaan dana yang berbasis saham.

7. Indeks Bisnis 27 yang merupakan indeks harga saham hasil kerja sama harian Bisnis Indonesia dengan BEI. Bisnis Indonesia dalam hal ini adalah pihak yang independen sehingga diharapkan dapat mengelola indeks secara lebih independen dan fleksibel. Pemilihan konstituen indeks adalah berdasarkan performa emiten dengan kriteria seleksi fundamental, historikal data transaksi (teknikal) dan akuntabilitas. Indeks ini baru diperkenalkan pada publik pada tanggal 27 Januari 2009.

8. Indeks Pefindo25, yaitu indeks yang dimaksudkan untuk memberikan tambahan pedoman investasi bagi pemodal yaitu dengan membuat suatu benchmark indeks baru yang secara khusus membuat performa saham emiten kecil dan menengah (Small Medium Enterprises/SME) melalui kriteria dan metodologi yang konsisten. Indeks ini baru diluncurkan pada tanggal 18 Mei 2009.

9. Indeks Sri-Kehati, yaitu indeks yang dibentuk untuk memberikan tambahan pedoman investasi bagi pemodal yang memiliki preferensi pada emiten yang memiliki performa yang sangat baik untuk mendorong usaha-usaha berkelanjutan, serta memiliki kesadaran terhadap lingkungan hidup, sosial dan tata kelola perusahaan yang baik. Adapun indeks ini merupakan kerjasama PT. BEI dengan Yayasan Keanekaragaman Hayati Indonesia (Yayasan Kehati) dan SRI merupakan kependekan dari Social and Responsible Investment. Indeks ini diluncurkan pada tanggal 8 Juni 2009, dengan jumlah 25 saham.

10. Indeks Papan Utama dan Papan Pengembangan, yaitu indeks yang memunjukkan kumpulan saham yang tercatat pada papan utama dan papan pengembangan. Papan Utama ditujukan untuk emiten yang mempunyai ukuran (size) besar dan mempunyai track record yang baik. Sementara, Papan Pengembangan dimaksudkan untuk perusahaan-perusahaan yang belum dapat memenuhi persyaratan pencatatan di papan utama, termasuk perusahaan yang mempunyai prospektif bagus namun belum menghasilkan keuntungan dan merupakan sarana bagi perusahaan yang sedang dalam penyertaan. Indeks ini diluncurkan pada tanggal 8 April 2002.

11. Indeks SMInfra18, yaitu indeks yang terdiri dari 18 saham yang konstituennya dipilih dari sektor-sektor infrastruktur utama ataupun beberapa sektor pendukung dalam pembangunan infrastruktur. Indeks ini mengacu pada hipotesis 'pembangunan infrastruktur' akan berperan penting terhadap perkembangan ekonomi Indonesia ke depan dan Pemerintah akan fokus pada pembangunan infrastruktur, maka infrastruktur menjadi sektor yang prospektif dan menarik bagi investor. Investor pasar modal (manajer investasi, dana pensiun, asuransi dan investor perorangan) membutuhkan referensi yang lebih spesifik terhadap sahamsaham infrastruktur sebagai acuan investasi.

Indeks tersebut pada dasarnya menggunakan metode perhitungan yang sama, yang membedakannya adalah jumlah saham yang digunakan sebagai komponen dalam perhitungannya. Keempat indeks tersebut ditampilkan terus menerus melalui display 
wall di lantai bursa dan disebar-luaskan ke data vendor melalui data feed.Adapun metodologi penghitungannya (BEI, 2010), adalah :

Dimana :

$$
\text { Indeks }=\frac{\text { Nilai Pasar }}{\text { Nilai Dasar }} \times 100
$$

Keterangan :

$$
\text { Nilai Pasar }=\mathrm{P}_{1} \mathrm{Q}_{1}+\mathrm{P}_{2} \mathrm{Q}_{2}+\ldots+\mathrm{P}_{\mathrm{i}} \mathrm{Q}_{\mathrm{i}}+\mathrm{P}_{\mathrm{n}} \mathrm{Q}_{\mathrm{n}}
$$

$\mathrm{P}=$ Closing Price (harga yang terjadi) untuk emiten ke-i

$\mathrm{Q}=$ Jumlah saham yang digunakan untuk perhitungan indeks

$\mathrm{n}=$ Jumlah emiten yang tercatat di BEI

\section{Risiko dan Return}

Dalam dunia yang penuh ketidak-pastian ini sangat sulit bagi para investor untuk memastikan secara tepat besarnya arus kas yang diharapkan akan diterima di masa yang akan datang. Salah satu pendekatan yang dilakukan adalah dengan menghitung arus kas yang diharapkan. Arus kas yang diharapkan merupakan rata-rata tertimbang dari arus kas yang mungkin dihasilkan. Berbicara tentang tingkat keuntungan (return), pasti tidak terlepas dari yang namanya risiko (risk). Tingkat keuntungan dan risiko merupakan dua hal yang tidak terpisah, karena pertimbangan suatu investasi merupakan trade-off atau pertukaran dari kedua faktor tersebut.

Risiko (risk) sering dihubungkan dengan penyimpangan atau deviasi dari outcome yang diterima dengan yang diharapkan. Van Horne (1997), mengatakan "risk is the variability of returns from those that are expected". Oleh karenanya, dimensi risiko ada dua yaitu menyimpang lebih kecil atau menyimpang lebih besar. Risiko merupakan variabilitas return terhadap return yang diharapkan. Risiko diwujudkan dalam bentuk standar deviasi yang mengukur nilai absolut penyimpangan dari nilai-nilai yang sudah terjadi dengan nilai rata-ratanya (sebagai nilai yang diharapkan).

Tandelilin (2010) menjelaskan bahwa sebagai visualisasi risiko maka digunakan perlambang yaitu, standar deviasi. Standar deviasi digunakan sebagai alat ukur risiko dari return realisasi. Lalu, untuk mengukur risiko dari return ekspektasi digunakan varian (variance). Varian tidak lain merupakan kuadrat dari standar deviasi.Terdapat tiga kemungkinan sikap dalam menghadapi risiko yang dapat kita identifikasikan (Jogiyanto, 2009):

1. Risk seeker adalah bahwa untuk tingkat return yang diharapkan yang sama besar, investor akan memilih investasi yang memiliki risiko yang lebih tinggi.

2. Risk averter adalah bahwa untuk tingkat return yang diharapkan yang sama besar, akan memilih investasi yang memiliki risiko yang lebih rendah.

3. Risk neutral adalah kelompok moderat, terletak antara kedua kelompok tersebut. Kelompok ini akan memilih investasi dengan tingkat return yang sesuai dengan risiko yang dihadapi.

Manajer bisnis dan pemegang saham pada umumnya dikategorikan ke dalam risk averter yaitu orang yang tidak menyukai risiko atau yang lebih menyukai tingkat keuntungan rata-rata yang tinggi dan varian return yang rendah.

\section{Analisis Teknikal}

Kunci sukses dalam investasi adalah pengetahuan dan action. Awalnya, analisis teknikal diaplikasikan di equity market tetapi kemudian secara bertahap kepopulerannya dikembangkan di pasar komoditi, instrumen-instrumen hutang, matauang, dan pasar- 
pasar internasional lainnya (Pring, 2002). Tidak ada alasan mengapa seseorang tidak dapat memperoleh keuntungan dipasar keuangan. Analisis teknikal amat berguna untuk memprediksi dan mengidentifikasikan emerging trends.

"Not earnings, nor dividends, nor risk, nor gloom of high interest rates stay the chartist from their assigned task: studying the price movements of stocks." Kata-kata tersebut sering dilontarkan orang di Wall Street (Malkiel, 1990). Para praktisi melihat bahwa dalam membeli saham yang terpenting adalah melihat kecenderungan dari "crowds" yang tercermin pada grafik-grafik (charts) seperti: trend following indicators, oscillator indicators, dan miscellaneous indicators.

Pendekatan teknikal untuk keputusan investasi merefleksikan ide bahwa harga bergerak dalam trends yang dicerminkan dengan perubahan perilaku investor dalam menaksirkan ekonomi, moneter, politik, dan psikologi. Seni pendekatan teknikal adalah identify trend changes at an early stage and to maintain an investment posture until the weight of the evidence indicates that the trend has reversed (Pring, 2002). Dasar pemikirannya adalah manusia sebagai makluk pada dasarnya kurang lebih konstan dan trend bereaksi pada situasi yang kurang lebih sama dengan cara yang konstan. Dengan mempelajari titik balik pasar sebelumnya akan dimungkinkan untuk melihat beberapa karakteristik yang dapat membantu mengidentifikasikan titik tertinggi dan titik terendah pasar.

Analisis teknikal berdasarkan atas asumsi bahwa orang akan selalu melakukan kesalahan yang sama seperti yang pernah dilakukan sebelumnya. Hubungan manusia amat komplek dan tidak pernah sama satu sama lainnya. Pasar yang merefleksikan keinginan orang tidak pernah identik dalam performance-nya tetapi kesamaan karakteristiknya dapat digunakan untuk menentukan major juncture points. Analisis teknikal membuat alat sebagai indikator dalam menangkap dan mengisolasi titik-titik yang mencerminkan cyclical market juncture.

Analisis teknikal dapat dibagai ke dalam 3 area pokok, yaitu: (1)sentiment, (2)flow-of-funds, dan (3)market structure indicators. Sentimen merupakan expectational indicators yang memonitor emosi para investor. Jadi indeks sentimen bergerak dari satu titik ekstrem pada bear market bottom ke bull market top. Asumsi indikator ini adalah kelompok investor yang berbeda konsisten dengan aksinya pada major market turning points. Flow-of-funds indicators menganalisis posisi finansial dari berbagai macam kelompok investasi untuk mengetahui potensinya dalam membeli dan menjual saham. Harga dimana transaksi tersebut terjadi harus sama antara pembeli dan penjual. Sehingga jumlah uang yang mengalir ke luar harus sama dengan uang yang mengalir masuk. Pendekatan flow-of-funds amat peduli dengan before-the-fact balance antar penawaran dan permintaan atau disebut hubungan ex ante.

Market structure indicators atau character of the market indicators memonitor trend dari berbagai indeks harga, market breadth, siklis, volume dan hal-hal lain dalam rangka mengevaluasi "kesehatan" bull dan bear markets. Biasanya, waktu, harga dan ukuran internal seperti market breadth, momentum, dan volume naik dan turun secara bersama-sama tetapi pada akhir gerakan pasar indikator-indikator ini akan menyimpang dari harganya. Analisis teknikal berdasarkan atas teori yang menyatakan bahwa harga merefleksikan psikologi massa (the crowd) dalam aksinya. Oleh karena itulah gerakan harga dimasa yang akan datang juga mendasarkan atas psikologi massa yang bergerak diantara rasa panik, ketakutan, dan rasa tidak percaya diri disatu sisi dengan rasa percaya diri, terlalu optimis, dan keserakahan disisi lainnya.

Pergerakan harga dapat diklasifikasikan dalam: (1) gerakan pokok atau primary/cyclical yang merefleksikan sikap investor terhadap siklus bisnis dengan 
periode 1 sampai 3 tahun; (2) intermediate dengan periode 3 minggu sampai beberapa bulan; dan (3) short term movement dengan periode 3 atau 4 minggu cenderung bersifat random.Beberapa konsep dalam analisis teknikal dapat dilihat dari beberapa adagium dibawah ini:

1. Market action discounts everything, "never what they (stocks) are worth but what people think they are worth" (Drew, 1968). Gerakan yang pokok dalam obligasi, saham, dan harga komoditas disebabkan oleh trend jangka panjang oleh emosi investasi yang dilakukan publik. Emosi ini mencerminkan tingkat antisipasi dan tingkat perkembangan aktiviras ekonomi dimasa datang dan sikap para investor terhadap aktivitas tersebut.

2. Prices move in trends. Pasar keuangan bergerak dalam trend yang disebabkan oleh adanya perubahan sikap dan ekspektasi investor terhadap siklus bisnis. Analisis teknikal mencoba untuk mengidentifikasi-kan titik belok (turning point) dari price trend secara rata-rata yang diakibatkan oleh kekuatan dan kelemahan laten struktur pasar. Trend dari optimisme investor mempengaruhi pergerakan harga. Aspek emosi dapat dilihat dari empat (4) dimensi, yaitu price, time, volume, danbreadth. Perubahan harga merefleksikan tingkat perubahan sikap investor. Waktu mengukur panjangnya siklus psikologi investor. Makin lama seorang investor untuk bergerak dari elemen bullish ke bearish, makin besar pula perubahan harga tersebut menuju kesuatu arah. Volume merefleksikan intensitas perubahan sikap investor. Breadth, mengukur lamanya emosi investor. Analisis teknikal mengukur dimensi psikologi dalam berbagai cara. Kebanyakan indikator memonitor dua atau lebih aspek secara simultan. Tidak ada satu indikatorpun yang dapat mengekspektasikan sinyal dari semua perubahan trend, maka amat perlu untuk menggunakan sejumlah indikator secara bersama-sama untuk membangun konsensus mengenai apa yang akan terjadi.

3. History repeats itself. Analisis teknikal mempercayai bahwa data historis mempengaruhi harga saham sekarang dan yang akan datang. Harga saham mempunyai pola yang selalu berulang-ulang sepanjang masa. Pola tersebut mengikuti pola peak-and-trough (puncak dan lembah) yang amat sederhana tetapi efektif mengidentifikasikan pergerakan saham.

Adapun penggunaan simulasi Monte Carlo untuk analisis teknikal, dalam hal ini berkaitan dengan volatilitas yang akan dilakukan dengan cara membangkitkan bilangan random berdasarkan karakteristik dari data yang akan dibangkitkan yang kemudian dapat digunakan untuk menduga volatilitas(Maruddani dan Purbowati, 2009).

\section{METODE PENELITIAN}

\section{Objek Penelitian}

Objek dari penelitian ini adalah harga saham-saham terkategori indeks konstituen. Oleh karena itu, maka data yang diperlukan adalah harga-harga saham yang masuk ke dalam Indeks Konstituen. Beberapa kelompok saham yang akan secara detail diamati, yaitu :

1. JII (Jakarta Islamic Index) yang menggambarkan 30 saham berbasis syariah yang likuid diantara saham yang terkategori syariah yang masuk didalam Daftar Efek Syariah.

2. Indeks LQ 45 yang terdiri dari 45 saham likuid yang aktif diperdagangkan di Bursa Efek Indonesia, sebagai proxy untuk investasi konvensional. 
3. SMInfra18, yang terdiri dari 18 saham yang konstituennya dipilih dari sektor-sektor infrastruktur utama ataupun beberapa sektor pendukung dalam pembangunan infrastruktur.

\section{Desain Penelitian}

Penelitian ini adalah penelitian arsip (archieval research), yaitu penelitian yang menggunakan sumber tertulis dari dokumen perusahaan, text-book, laporan keuangan perusahaan dan pengungkapan yang dilakukan oleh perusahan yang berkaitan dengan data-data keuangan (Smith, 2003). Adapun metode penelitian yang digunakan adalah analisis deskriptif verifikatif. Analisis deskriptif dilakukan dengan cara mengumpulkan saham-saham yang menjadi unit observasi, kemudian mengukur volatilitas harga saham dengan menggunakan simulasi Monte Carlo. Setelah, langkah penelitian awal dikerjakan maka langkah yang kedua adalah melakukan proses verifikasi untuk mengetahui signifikansi perbedaan volatilitas harga saham pada beberapa indeks terkategori indeks konstituen di Bursa Efek Indonesia.

\section{Operasionalisasi Variabel :}

Dalam penelitian ini variabel-variabel yang diteliti adalah :

1. Harga Saham, yaitu harga bulanan dari saham-saham yang terkategori indeks konstituen, satuannya adalah Rupiah.

2. Volatilitas Harga, yaitu nilai yang diperoleh setelah menjalankan serangkaian prosedur Simulasi Monte-Carlo terhadap harga saham.

\section{Jenis, Cara Penentuan, dan Sumber Data Jenis dan Cara Penentuan Data}

Jenis data adalah data sekunder, berupa laporan pergerakan harga-harga saham bulanan yang termasuk ke dalam Indeks Konstituen. Kurun waktu pengumpulan data yaitu selama periode Juli 2000 s/d Juli 2018. Oleh karena indeks tersebut mulai diterbitkan pada tahun yang berbeda, maka perbandingan yang sifatnya komprehensif juga akan dilakukan untuk secara berbeda. Setelah data dikumpulkan, kemudian data harga saham diolah, disusun dalam bentuk tabel. Adapun dalam proses komputasinya digunakan program Microsoft Excel dengan add-ins simulasi Monte-Carlo.

Perbedaan hasil yang kemungkinan akan muncul diidentifikasi terjadi sematamata karena proses screening pada saat awal alokasi aset. Portofolio akan terindikasi terlebih dahulu melalui proses filterisasi (screening process) di masing-masing indeks, sementara itu proses investasi yang lainnya dapat dikatakan sama. Oleh karena itu, dengan pola investasi yang dilakukan secara mandiri, maka diasumsikan bahwa investor akan menerapkan konsep manajerial yang sama terhadap kedua jenis investasi tersebut. Hal ini yang kemungkinan akan mengakibatkan munculnya kekhawatiran akan misleading akibat faktor tipe manajemen dan proses keputusan investasinya dapat disingkirkan.

Adapun data yang digunakan adalah data sekunder yang dikeluarkan oleh PT. BEI dan ECFIN yaitu data pergerakan saham yang termasuk kategori indeks konstituen.

\section{Sumber data}

Data yang diperlukan dalam penelitian diperoleh dengan melakukan dokumentasi dan studi terhadap arsip atau data yang terangkum dalam ICMD (Indonesian Capital Market Directory) 2000-2018. Data yang diperlukan untuk penelitian ini mencakup seluruh populasi saham yang masuk dalam indeks konstituen. 
Saham-saham tersebut adalah unit observasi dan akan diamati pergerakannya dalam kurun waktu penelitian 2000-2018

\section{Prosedur Analisis Data}

Penggunaan metode simulasi Monte Carlo adalah salah satu cara untuk mengukur volatilitas. Simulasi Monte Carlo mempunyai beberapa jenis algoritma. Namun, pada intinya adalah melakukan simulasi dengan membangkitkan bilangan random untuk mengestimasi nilai volatilitas dari harga saham. Adapun pengukuran volatilitas dengan Simulasi Monte Carlo dilakukan dengan mengasumsikan bahwa harga saham yang disimulasikan menggunakan parameter yang sesuai dan tidak mengasumsikan bahwa return bersifat linear. Algoritma sederhana perhitungan volatilitas menggunakan simulasi Monte Carlo, Render (1998) menjelaskan tahapan dalam Simulasi Monte Carlo dapat dibagi menjadi 5 tahap sebagai berikut:

1. Membuat distribusi probabilitas. Salah satu cara umum yang dilakukan untuk membuat distribusi probabilitas suatu variabel adalah mengamati data historis. Probabilitas dari tiap data dapat diperoleh dengan membagi frekuensi dengan jumlah total observasi jika diasumsikan data di masa lalu akan terjadi di masa mendatang. Tahap membuat distribusi probabilitas sebagai berikut:

a. Menentukan batas maksimal dan minimal data dari 267 data.

b. Menentukan interval kelompok (bins). Dalam uji coba menggunakan bins $=0.01$ yang batasannya adalah maksimal dan minimal data sampling.

c. Menentukan jumlah sampling yang masuk kelompok (bins).

d. Menyusun distribusi kumulatif untuk tiap variabel.

e. Menyusun interval bilangan random. Generate random numbers sebanyak 10.000 simulasi.

2. Persentase frekuensi kumulatif dari data input (imbal hasil) menjadi interval (bins).

3. Menghasilkan bilangan random. Random number dikelompokkan ke dalam bins.

4. Mensimulasikan eksperimen.

a. Menentukan prediksi imbal hasil masing-masing binsyang merupakan perkalian bins dengan frekuensi.

b. Menentukan mean dari imbal hasil yang diharapkan yang merupakan prediksi imbal hasil $t+1$.

Pada penelitian ini simulasi Monte Carlo akan dikomputasi menggunakan addins dari CUniversitas Padjadjaran.

\section{Pengujian Hipotesis}

Adapun pengujian hipotesis dilakukan untuk menjawab pertanyaan penelitian sebagai berikut :

"Apakah volatilitas harga saham terkategori indeks kontituen yang diukur dengan Monte Carlo Simulation benar-benar berbeda dan signifikan?"

Untuk menjawab hipotesis tersebut maka dilakukan pengujian terhadap variabel Volatilitas Harga Saham. Pengujian hipotesis tersebut dilakukan dengan menjalankan uji beda pada program IBM SPSS Statistics Version 25, langkahlangkahnya adalah sebagai berikut:

1. Menentukan varians sampel yang akan diuji, dalam penelitian ini, parameter yang akan diuji adalah Volatilitas Harga Saham.

2. Penentuan hipotesis, langkah ini dilakukan untuk menjawab masing-masing hipotesis yang telah diajukan, maka akan ada dua null hypothesis dan alternative hypothesis: 
a. Ho: tidak terdapat perbedaan yang signifikan antara volatilitas harga saham terkategori indeks konstituen

b. $\mathrm{H}_{1}$ : terdapat perbedaan yang signifikan antara volatilitas harga saham terkategori indeks konstituen

3. Penentuan taraf nyata (level of significance), dalam penelitian ini, taraf nyata yang digunakan adalah $\alpha=0,05=5 \%$

4. Penentuan statistik uji Statsistik uji yang digunakan adalah uji F, dimana :

5.

$$
\mathrm{F}_{\text {statistic }}=\frac{\mathrm{MS}_{\mathrm{B}}}{\mathrm{MS}_{\mathrm{W}}}
$$

dimana :

$\mathrm{MS}_{\mathrm{B}}=$ Mean Square Between Groups

$\mathrm{MS}_{\mathrm{W}}=$ Mean Square Within Groups

6. Menentukan daerah kritis (critical area) dan titik kritis (critical point) serta daerah penerimaan $\mathrm{H}_{\mathrm{o}}$

a. Daerah kritis atau daerah penolakan $\mathrm{H}_{\mathrm{o}}$ adalah daerah dimana apabila $\mathrm{F}_{\text {statistic }}$ terletak di daerah ini akan menyebabkan $\mathrm{H}_{\mathrm{o}}$ ditolak

b. Daerah penerimaan $\mathrm{H}_{\mathrm{o}}$ adalah daerah diluar daerah kritis, dimana apabila $\mathrm{F}_{\text {statistic }}$ terletak didaerah ini akan menyebabkan $\mathrm{H}_{\mathrm{o}}$ diterima

7. Nilai titik kritis ditentukan oleh statistik uji yang digunakan yaitu, uji F. Kriteria pengujian hipotesis adalah :

a. Jika $\mathrm{F}_{\text {statistic }} \leq \mathrm{F}_{\text {tabel, }}$ maka Ho diterima dan $\mathrm{H}_{1}$ ditolak berarti Null Hypothesis diterima. Apabila Ho diterima berarti tidak terdapat perbedaan yang signifikan antara volatilitas harga saham terkategori indeks konstituen.

b. Jika $\mathrm{F}_{\text {statistic }} \geq \mathrm{F}_{\text {tabel}}$, maka Ho ditolak dan $\mathrm{H}_{1}$ diterima berarti Alternative Hypothesis diterima. Apabila Ho ditolak berarti terdapat perbedaan yang signifikan antara volatilitas harga saham terkategori indeks konstituen.

\section{HASIL PENELITIAN DAN PEMBAHASAN}

\section{Hasil Penelitian}

Pada bagian sebelumnya indikator yang digunakan untuk melakukan evaluasi terhadap risiko adalah volatilitas harga saham dengan menggunakan simulasi Monte Carlo. Sebagai indikator risiko, volatilitas harga saham dibandingkan antara tiga (3) kelompok indeks terkategori indeks konstituen di Bursa Efek Indonesia. Hal ini sejalan dengan penggambaran risiko sebagai suatu keseluruhan dengan menghitung baik risiko sistematis maupun non-sistematis yang ditanggung oleh investor.

Sebagaimana diketahui selain pasar modal konvensional, di Bursa Efek Indonesia terdapat pula pasar modal syariah. Pasar modal syariah dimulai ketika JII diperkenalkan pada 3 Juli 2000 bersamaan dengan dikenalkannya reksadana syariah. Sementara itu, indeks LQ 45 telah lebih dulu diperkenalkan, sebagai indeks yang terdiri dari 45 saham terbaik yang diperdagangkan di Bursa Efek Indonesia dengan tingkat kapitalisasi yang tinggi, maka indeks LQ 45 hampir selalu menjadi benchmark bagi indeks konstituen lainnya. Berbeda dengan JII dan LQ 45 yang merupakan kumpulan beberapa saham yang aktif diperdagangkan, SMInfra 18 merupakan sekelompok saham yang memang menitik-beratkan pada sektor infrastruktur, oleh karena itu, saham ini digunakan sebagai acuan untuk melihat sektor-sektor utama pendukung perkembangan ekonomi dan pembangunan yang ada di Indonesia. 


\section{Perbandingan Prediksi Harga Saham untuk Saham-saham pada Kelompok Indeks JII, LQ 45, dan SMInfra 18}

Didalam penggunaan simulasi Monte Carlo, untuk dapat melakukan pengukuran volatilitas harga saham (Render, 1998), maka langkah awal yang harus dilakukan adalah melakukan forecasting atau prediksi terhadap harga saham atau mean $n_{t+1}$. Prediksi terhadap harga saham inilah yang kemudian menjadi acuan pengukuran volatilitas-nya dengan melihat nilai standar deviasi setelah iterasi atau pengulangan dilakukan dengan membangkitkan nilai random (acak) sebanyak 1000 kali percobaan. Didalam periode observasi Juli 2000 s.d Juli 2018 dapat dibandingkan prediksi harga saham dari berbagai saham yang pada kelompok indeks JII, LQ 45, dan SMInfra 18 dengan menggunakan Simulasi Monte Carlo (Monte Carlo Simulation/MCS). Berikut grafik yang menggambarkan forecast harga saham dari kelompok indeks JII, LQ 45, dan SMInfra 18 periode Juli 2000 s.d Juli 2018:

Grafik 1. Forecast (Prediksi) Harga Saham-saham Kelompok Indeks JII, LQ 45, dan SMInfra 18 dengan Menggunakan Simulasi Monte Carlo (MCS)

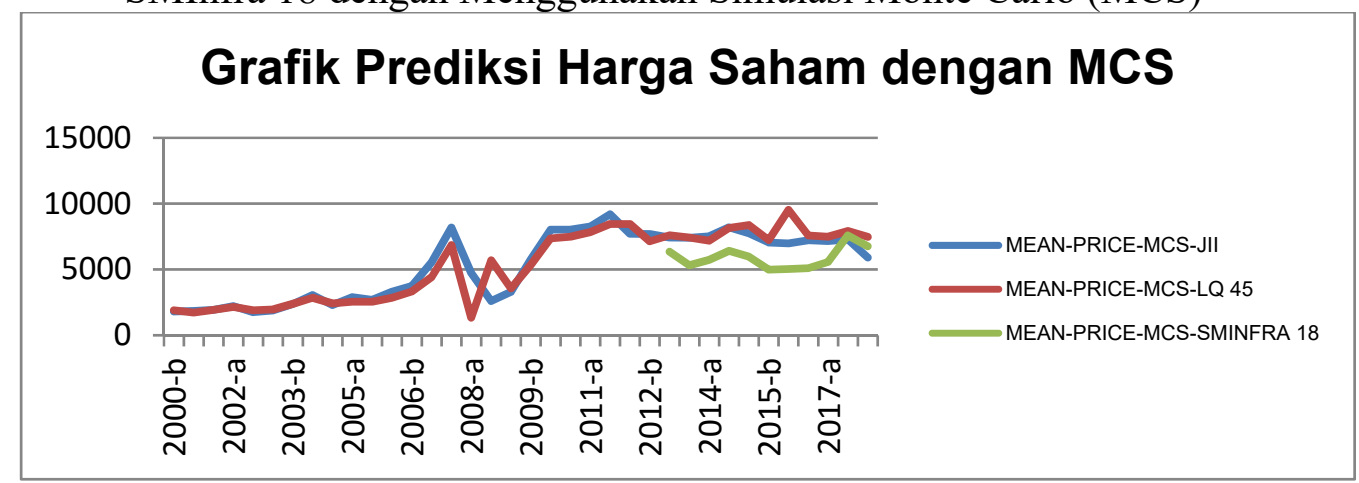

Berdasarkan grafik prediksi diatas, dapat dilihat bahwa harga saham-saham dalam kelompok Indeks JII, LQ 45, dan SMInfra 18, menunjukkan bahwa harga sahamsaham SMInfra 18 berada dibawah dua kelompok indeks yang telah lama dikenal oleh investor. Grafik diatas menunjukkan superioritas dari indeks LQ 45, sebagai indeks yang menjadi benchmark, harga saham kelompok ini nampak jauh melampaui dua indeks lainnya, bahkan terdeteksi menduduki posisi harga tertinggi untuk semester kedua di tahun 2015. Selanjutnya pada grafik dibawah akan diperbandingkan volatilitas harga saham dari kelompok indeks JII, LQ 45, dan SM Infra 18.

Grafik 2. Perbandingan Volatilitas Harga Saham-saham Indeks JII, LQ 45, dan SMInfra 18 untuk Periode Observasi Juli 2000 s.d Juli 2018

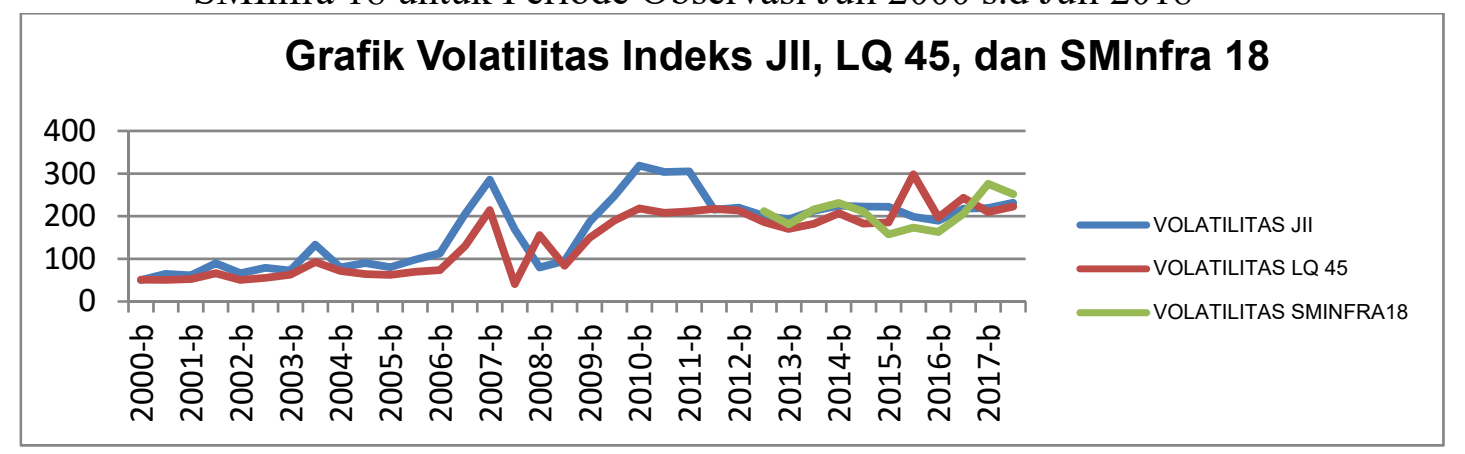


Selanjutnya, pola volatilitas harga saham justru menunjukkan adanya perbedaan di masing-masing kelompok indeks. Kelompok indeks JII menunjukkan tingkat volatilitas yang lebih tinggi, begitu pula kelompok indeks SMInfra 18, bahkan nampak melampaui volatilitas indeks lainnya. Lebih lanjut lagi hasil statistik deskriptif dari keseluruhan data dapat dilihat pada tabel dibawah ini:

Tabel 2. Statistik Deskriptif

\begin{tabular}{|l|r|r|r|r|r|}
\hline & N & Minimum & Maximum & Mean & Std. Deviation \\
\hline Volatilitas & 83 & 40.6900 & 318.6473 & 162.176671 & 75.2472493 \\
\hline Valid N (listwise) & 83 & & & & \\
\hline
\end{tabular}

Dari tabel diatas dapat dilihat rata-rata pengukuran volatilitas harga saham dari tiga (3) kelompok indeks, yaitu JII, LQ 45 dan SMInfra 18 memiliki nilai 162,17. Kendati demikian dari data diatas dapat dilihat nilai terendah adalah 40.69 sementara nilai tertinggi menunjukkan angka 318.64 .

\section{Uji Hipotesis}

Sebelumnya telah diuraikan statistik deskriptif ketiga portofolio saham yang telah terbentuk. Melalui gambaran tersebut terlihat bahwa volatilitas harga saham menunjukkan angka terendah dan angka tertinggi. Langkah selanjutnya adalah menguji hipotesis yang diajukan pada bab sebelumnya yaitu berkaitan dengan apakah terdapat perbedaan yang signifikan antara volatilitas harga saham untuk kelompok indeks JII, LQ 45, dan SMInfra 18. Untuk menentukan uji beda yang tepat maka uji normalitas dijalankan. Hal ini terkait dengan pendekatan statistik parametrik ataukah non parametrik yang akan digunakan. Tabel dibawah ini akan menampilkan hasil uji normalitas pada data volatilitas harga saham ketiga indeks konstituen tersebut

Tabel 3. Hasil Uji Normalitas pada saham indeks JII, LQ 45, dan SMInfra 18

\begin{tabular}{|c|c|c|c|c|c|c|c|}
\hline \multicolumn{8}{|c|}{ Tests of Normality } \\
\hline & \multirow[b]{2}{*}{ Indeks } & \multicolumn{3}{|c|}{ Kolmogorov-Smirnov ${ }^{\mathrm{a}}$} & \multicolumn{3}{|c|}{ Shapiro-Wilk } \\
\hline & & Statistic & $\mathrm{df}$ & Sig. & Statistic & $\mathrm{df}$ & Sig. \\
\hline \multirow{3}{*}{$\begin{array}{l}\text { Volatilita } \\
\text { S }\end{array}$} & JII & .170 & 36 & .010 & .912 & 36 & .007 \\
\hline & LQ 45 & .187 & 36 & .003 & .883 & 36 & .001 \\
\hline & SMInfra 18 & .133 & 11 & $.200^{*}$ & .956 & 11 & .725 \\
\hline
\end{tabular}

Pada tabel diatas dapat dilihat uji normalitas dengan Kolmogorov-Smirnov dan Shapiro-Wilk menunjukkan bahwa data volatilitas tidak memenuhi asumsi normalitas. Dengan demikian maka uji beda akan dilakukan dengan pendekatan statistik non parametrik, yaitu uji Kruskal Wallis untuk melihat signifikansi perbedaan volatilitas ketiga kelompok indeks tersebut, selanjutnya uji Mann Whitney dilakukan sebagai uji post hoc untuk melihat bagaimana signifikansi perbedaan antar kelompok indeks tersebut. 
Tabel 4. Hasil Uji Kruskal Wallis pada Volatilitas Harga Saham untuk Tiga Kelompok Indeks

\begin{tabular}{|l|r|}
\hline \multicolumn{2}{|c|}{ Test Statistics $^{\text {a,b }}$} \\
\hline & \multicolumn{1}{|c|}{ Volatilitas } \\
\hline Kruskal-Wallis H & 2.948 \\
\hline Df & 2 \\
\hline Asymp. Sig. & .031 \\
\hline a. Kruskal Wallis Test & \\
\hline b. Grouping Variable: Indeks & \\
\hline \multicolumn{2}{|l}{} \\
\hline
\end{tabular}

Hasil uji Kruskal Wallis menunjukkan bahwa secara statistik pada tiga kelompok indeks tersebut terdapat perbedaan yang signifikan pada volatilitas harga saham yang diukur dengan menggunakan simulasi Monte Carlo. Tabel di bawah ini akan selanjutnya menjelaskan pemeringkatan volatilitas pada kelompok indeks tersebut.

Tabel 5. Pemeringkatan Volatilitas Harga Saham berdasarkan uji Kruskal Wallis untuk Tiga Kelompok Indeks Konstituen

Ranks

\begin{tabular}{|l|l|r|r|}
\hline & \multicolumn{1}{|c|}{ Indeks } & \multicolumn{1}{c|}{ N } & \multicolumn{1}{c|}{ Mean Rank } \\
\hline \multirow{5}{*}{ Volatilitas } & JII & 36 & 45.25 \\
\cline { 2 - 4 } & LQ 45 & 36 & 34.83 \\
\cline { 2 - 4 } & SMInfra 18 & 11 & 54.82 \\
\cline { 2 - 4 } & Total & 83 & \\
\hline
\end{tabular}

Berdasarkan tabel diatas dapat dilihat bahwa SMInfra 18 ternyata memiliki volatitilas harga saham yang paling tinggi, disusul oleh JII dan kemudian oleh LQ 45. Uji post hoc selanjutnya dilakukan untuk melihat apakah perbedaan yang signifikan tersebut menunjukkan lebih kecil atau lebih besar dibandingkan dengan kelompok lainnya, uji post hoc Mann Whitney dapat dilakukan pada dua kelompok. Uji post hoc dilakukan untuk melihat signifikansi perbedaan yang menunjukkan lebih kecil atau lebih besar antar dua kelompok. Uji Mann Whitney dilakukan secara bertahap sebagaimana disajikan pada tabel dibawah ini:

Tabel 6. Uji Mann Whitney JII dan SMInfra 18

\begin{tabular}{|l|r|}
\multicolumn{2}{|c|}{ Test Statistics } \\
\hline \multicolumn{2}{|c|}{} \\
\hline Mann-Whitney U & \multicolumn{1}{c|}{ Volatilitas } \\
\hline Wilcoxon W & 150.000 \\
\hline Z & 816.000 \\
\hline Asymp. Sig. (2-tailed) & -1.206 \\
\hline Exact Sig. [2*(1-tailed Sig.)] & .228 \\
\hline a. Grouping Variable: Indeks & $.236^{\text {b }}$ \\
\hline b. Not corrected for ties. \\
\hline
\end{tabular}


Ranks

\begin{tabular}{|l|c|c|c|c|}
\hline \multirow{3}{*}{ Volatilitas } & Indeks & N & Mean Rank & Sum of Ranks \\
\hline & JII & 36 & 22.67 & 816.00 \\
\cline { 2 - 5 } & SMInfra 18 & 11 & 28.36 & 312.00 \\
\cline { 2 - 5 } & Total & 47 & & \\
\hline
\end{tabular}

Berdasarkan tabel Uji Post Hoc di atas dapat dilihat bahwa tidak terdapat perbedaan yang signifikan antara indeks JII dan SMInfra 18, sehingga kendati hasil pemeringkatan menunjukkan bahwa SMInfra 18 volatilitas harga sahamnya lebih tinggi sesungguhnya tidak terdapat perbedaan antara volatilitas harga saham dua kelompok indeks tersebut.

Tabel 7. Uji Mann Whitney JII dan LQ 45

Test Statistics ${ }^{\mathrm{a}}$

\begin{tabular}{|l|r|}
\hline & \multicolumn{1}{|c|}{ Volatilitas } \\
\hline Mann-Whitney U & 483.000 \\
\hline Wilcoxon W & 1149.000 \\
\hline Z & -1.858 \\
\hline Asymp. Sig. (2-tailed) & .063 \\
\hline a. Grouping Variable: Indeks & \\
\hline
\end{tabular}

\begin{tabular}{|l|l|r|r|r|}
\hline \multicolumn{1}{|c|}{ Ranks } \\
\hline \multirow{3}{*}{ Volatilitas } & \multicolumn{1}{|c|}{ Indeks } & N & \multicolumn{1}{c|}{ Mean Rank } & \multicolumn{1}{c|}{ Sum of Ranks } \\
\cline { 2 - 6 } & JII & 36 & 41.08 & 1479.00 \\
\cline { 2 - 6 } & LQ 45 & 36 & 31.92 & 1149.00 \\
\cline { 2 - 5 } & Total & 72 & & \\
\hline
\end{tabular}

Berdasarkan tabel Uji Post Hoc di atas dapat dilihat bahwa tidak terdapat perbedaan yang signifikan antara indeks JII dan SMInfra 18, sehingga kendati hasil pemeringkatan menunjukkan bahwa SMInfra 18 volatilitas harga sahamnya lebih tinggi sesungguhnya tidak terdapat perbedaan antara volatilitas harga saham dua kelompok indeks tersebut.

Tabel 8. Uji Mann Whitney LQ 45 dan SMInfra 18

Test Statistics ${ }^{\text {a }}$

\begin{tabular}{|l|r|}
\hline & \multicolumn{1}{|c|}{ Volatilitas } \\
\hline Mann-Whitney U & 105.000 \\
\hline Wilcoxon W & 771.000 \\
\hline Z & -2.337 \\
\hline Asymp. Sig. (2-tailed) & .019 \\
\hline Exact Sig. [2*(1-tailed Sig.)] & $.019^{\mathrm{b}}$ \\
\hline a. Grouping Variable: Indeks & \\
\hline b. Not corrected for ties. & \\
\hline
\end{tabular}


Ranks

\begin{tabular}{|l|l|r|r|r|}
\hline & \multicolumn{1}{|c|}{ Indeks } & \multicolumn{1}{c|}{ N } & Mean Rank & \multicolumn{1}{c|}{ Sum of Ranks } \\
\hline \multirow{5}{*}{ Volatilitas } & LQ 45 & 36 & 21.42 & 771.00 \\
\cline { 2 - 5 } & SMInfra 18 & 11 & 32.45 & 357.00 \\
\cline { 2 - 5 } & Total & 47 & & \\
\hline
\end{tabular}

Berdasarkan tabel Uji Post Hoc di atas dapat dilihat bahwa terdapat perbedaan yang signifikan antara indeks LQ 45 dan SMInfra 18, sehingga hasil pemeringkatan yang menunjukkan bahwa SMInfra 18 volatilitas harga sahamnya lebih tinggi dibandingkan indeks LQ 45 adalah menunjukkan data yang sesungguhnya.

\section{Pembahasan}

Hasil penelitian menunjukkan keberartian perbedaan volatilitas harga saham yaitu, volatilitas harga saham indeks LQ 45 yang paling rendah dibandingkan indeks saham lainnya. Kendati uji post hoc menunjukkan tidak ada perbedaan yang signifikan antara kelompok JII dan LQ 45, akan tetapi pemeringkatan menunjukkan bahwa volatilitas harga saham LQ 45 lebih rendah. Hal ini menunjukkan superioritas pasar konvensional terhadap syariah terkait risiko yang mengacu pada volatilitas harga saham. Dari hasil serangkaian tes statistik terlihat dengan jelas kumpulan saham LQ 45 menunjukkan kinerja yang lebih baik dari kelompok saham terkategori indeks konstituen lainnya. Hal ini disebabkan pembentukan prediksi harga saham sebagai indikator yang tinggi mampu memberikan volatilitas harga saham atau indikator risiko yang sewajarnya. Hasil dari penelitian tersebut menunjukkan bahwa investasi di pasar modal konvensional lebih superior dibandingkan pasar modal syariah maupun sektoral.

Hal ini juga memberi indikasi bahwa pemodelan dalam pembentukan portofolio yang mengacu pada indeks unggulan menjadi kunci utama bagi penelitian selanjutnya untuk dapat mengungkapkan perilaku investasi di pasar modal berdasarkan aliran gain dan loss yang menunjukkan nilai investasi yang sesungguhnya. Mengacu pada hasil diatas juga dapat dilihat bahwa penambahan objek observasi dengan menambah satu kelompok, yaitu SMInfra 18, sebagai kelompok yang mewakili populasi dari indeks konstituen berbasis sektor, ternyata memiliki andil besar terhadap signifikansi uji hipotesis. Penambahan kelompok SMInfra 18 memperlihatkan bahwa hingga saat ini superioritas dari pasar konvensional teruji, apabila investor mengacu pada portofolio theory dimana hanya satu model kombinasi portofolio optimal yang mungkin diambil dari serangkaian pilihan, maka pasar konvensional selalu lebih baik. Di lain pihak, serangkaian tes statistik juga membuktikan bahwa perbedaan yang terjadi adalah signifikan atau nyata. Berdasarkan pada kedua hasil tersebut, kembali lagi kepada investor, bahwa pasar modal memberikan banyak pilihan bagi investor, investor dituntut untuk memahami dan mempelajari berbagai indeks yang representatif sesuai dengan preferrensi-nya masing-masing.

Pasar modal syariah sebagai bagian indeks konstituen, selama ini ditawarkan sebagai alternatif investasi bagi yang ingin berinvestasi dalam tata kaidah syar'i sehingga untuk pasar modal khusus seperti pasar modal syariah. Tujuan investasi tersebut yang semestinya dikedepankan sehingga selanjutnya pilihan atau alternatif investor dapat diakomodir dengan variasi indeks dalam pasar modal syariah. Berabagai macam indeks dapat dikembangkan mengacu pada keberadaan pasar modal syariah, sejalan dengan hasil penelitian ini pasar modal syariah kini memperkenalkan indeks JII70 yaitu 70 saham syariah paling likuid yang tercatat di BEI. Review saham syariah yang menjadi konstituen JII70 dilakukan sebanyak dua kali dalam setahun, Mei dan 
November, mengikuti jadwal review DES oleh OJK. BEI menentukan dan melakukan seleksi saham syariah yang menjadi konstituen JII70. Adapun kriteria likuditas yang digunakan dalam menyeleksi 70 saham syariah yang menjadi konstituen JII70 adalah sebagai berikut:

- Saham syariah yang masuk dalam konstituen Indeks Saham Syariah Indonesia (ISSI) telah tercatat selama 6 bulan terakhir

- Dipilih 150 saham berdasarkan urutan rata-rata kapitalisasi pasar tertinggi selama 1 tahun terakhir

- Dari 150 saham tersebut, kemudian dipilih 70 saham berdasarkan rata-rata nilai transaksi harian di pasar regular tertinggi.

- 70 saham yang tersisa merupakan saham terpilih.

Investor kembali lagi harus selektif memilih investasi, semakin banyak alternatif saham yang ditawarkan dalam sebuah indeks volatilitas harga saham akan mengikuti seiring dengan fluktuasi harga saham tersebut. Investor harus cermat dalam memilih untuk menghindari berbagai macam keputusan irrasional dikarenakan penggunaan analisis teknikal yang tidak komprehensif dengan analisis fundamental.

\section{Kesimpulan}

\section{KESIMPULAN DAN SARAN}

Berdasarkan hasil penelitian dan pembahasan volatilitas harga saham pada tiga (3) kelompok indeks yaitu JII, LQ 45, dan SMInfra 18 dapat ditarik kesimpulan sebagai berikut:

1. Mengacu pada hasil uji statistik dengan menggunakan uji Kruskal Wallis, terdapat perbedaan yang signifikan antara volatilitas harga saham pada tiga kelompok indeks konstituen yang diajukan. Pemeringkatan menunjukkan bahwa SMInfra 18 menunjukkan volatilitas harga saham yang tertinggi, diikuti oleh JII, dan yang terendah adalah indeks LQ 45.

2. Uji post hoc dilakukan dengan uji Mann Whitney untuk mengurai signifikasi perbedaan ini, uji dilakukan berpasangan dengan hasil adanya perbedaan yang tidak signifikan antara indeks JII dan LQ 45, dengan pemeringkatan volatilitas JII lebih tinggi daripada indeks LQ 45.

3. Uji post hoc Mann Whitney menunjukkan bahwa tidak terdapat perbedaan antara indeks JII dan SMInfra 18, dengan volatilitas harga saham SMInfra 18 lebih tinggi dibandingkan dengan indeks JII.

4. Terdapat perbedaan signifikan antara LQ 45 dan SMInfra 18, dengan volatilitas harga saham LQ 45 lebih rendah dibandingkan dengan SMInfra 18. Hal ini menunjukan superioritas dari indeks LQ 45.

\section{Saran}

1. Investor yang melakukan investasi di pasar modal Indonesia sudah semestinya benar-benar memahami kaidah investasi sehingga pemilihan portofolio akan lebih bervariasi.

2. Perhitungan risiko dengan menggunakan volatilitas harga saham kerap kali menunjukkan bahwa risiko tidak berdiri sendiri, akan tetapi berdispersi sesuai dengan variabel lain yang dijadikan faktor tertimbang. Faktor tertimbang termaksud adalah harga saham, oleh karena itu, penelitian selanjutnya semestinya dapat mengakomodir aplikasi portofolio dengan fokus pada strategi indexing agar 
kemudian dapat dengan sesungguhnya dievaluasi masing-masing kinerja dari indeks yang ada di bursa efek indonesia.

\section{DAFTAR PUSTAKA}

Drew, G., 1968, New Methods for Profit in the Stock Market, Metcalfe Press, BostonUSA

Economis and Finance Institute, 2013, Indonesian Capital Market Directory, ECFIN

Farrell Jr, James L, 1997, Portfolio Management Theory \& Application-International Edition, Singapore, Mc Graw Hill

Firdaus, Achmad, 2004, Analisis Tracking Error : Suatu Kajian pada Kinerja Jakarta Islamic Index (JII) terhadap Indeks Harga Saham Gabungan (IHSG), Thesis Program Pascasarjana FE-UI

Gitman, Lawrence, 2003, Principles of Managerial Finance, USA, Pearson Addison Wesley

Jogiyanto, Hartono, 2009, Teori Portofolio dan Analisis Investasi, LPFE Universitas Gajah Mada

Malkiel, Burton G, 1996, A Random Walks Down Wall Street, $6^{\text {th }}$ ed, WW Norton Inc

Maruddani, D. Asih I., A Purbowati, 2009, Pengukuran Value at Risk pada Aset Tunggal dan Portofolio dengan Simulasi Monte Carlo, Jurnal Media Statistika. Vol 2. Issue 2. Pp 93-104, Program Studi Statistik FMIPA UNDIP

Pring, M.J., 2002, Technical Analysis Explained $4^{\text {th }}$ ed., McGraw-Hill

Render, Barry Jr., and Stair, Ralph. M, 1997, Quantitative Analysis for Management, Prentice-Hall Inc., New Jersey

Smith, Malcolm, 2003, Research Methods in Accounting, London, Sage Publications

Sunaryo, T., 2007, Manajemen Risiko Finansial, Jakarta, Salemba Empat

Tandelilin, Eduardus, 2010, Portofolio dan Investasi : Teori dan Aplikasi, Jakarta, Kanisius

Van Horne, James C, et al ,1997, Fundamentals of Financial Management, Prentice Hall College

Viney, Christopher and Phillips Peter, 2012, Financial Institutions, Instruments \& Markets, $7^{\text {th }}$ ed., McGraw Hill-Australia, Sydney-Australia 